\title{
Alterations in the Protein Composition of Maturing Phagosomes
}

Alan Pitt, * Luis S. Mayorga, ${ }^{*}$ Philip D. Stahl, * and Alan L. Schwartz ${ }^{\text {II }}$

Edward Mallinkrodt "Department of Pharmacology, ${ }^{*}$ Cell Biology and Physiology, and ${ }^{\S}$ Pediatrics, Washington University

School of Medicine, St. Louis, Missouri 63110; and ${ }^{\ddagger}$ Instituto de Histologia y Embriologia

(CONICET-Universidad Nacional de Cuyo), Mendoza, Argentina 550

\begin{abstract}
We investigated the protein composition of J774-E clone macrophage phagosomes isolated at different stages of phagolysosome biogenesis. Phagosomes formed by internalizing antibody-coated Staphylococcus aureus for 3 min followed by chase for $0,4,9$, or 15 min were isolated by density gradient centrifugation. Enrichment and purity of the phagosome preparations were quantitated by radiolabeled ligand recovery, enzyme markers, and electron microscopy. One-dimensional SDSPAGE analyses of the isolated phagosomes revealed virtually identical protein compositions. However, Western blot analyses with antibodies directed against selected proteins of known itineraries along the endocytic pathway demonstrated distinct differences in phagosome protein compositions. Accumulating within the maturing phagosome were the $31-\mathrm{kD}$ subunit of the vacuolar proton pump, cathepsin $D, \beta$-glucuronidase, the cation dependent mannose 6-phosphate receptor, and LAMP-1. Decreasing within the maturing phagosome were the FcII receptor, the mannose receptor, and alpha-adaptin. These results indicate that although the macrophage phagosome's total protein composition changes little during phagolysosome formation, the maturing phagosome both receives and eliminates, possibly by protein recycling, specific membrane and sequestered proteins. (J. Clin. Invest. 1992. 90:1978-1983.) Key words: phagocytosis • endocytosis • protein sorting • vesicle fusion • vesicle maturation
\end{abstract}

\section{Introduction}

Phagocytosis, a process used by specialized cells termed phagocytes, describes the engulfment of relatively large extracellular particles (1). The resulting intracellular vacuole, the phagosome, is subsequently transformed into an acidic, oxidizing, and hydrolase-rich phagolysosome. The transition from early phagosome to phagolysosome involves both the influx and efflux of material. Recently, Mayorga et al. described the sequential fusion in vivo of endosomes and lysosomes to phagosomes (2). Muller et al. provided evidence for recycling of membrane protein from phagosome by demonstrating that within $30 \mathrm{~min}$ at $37^{\circ} \mathrm{C}$, a majority of the phagosome's iodinatable proteins can relocate to the plasma membrane (3). In addition, we recently showed that phagocytosed protein can migrate to and

Address correspondence to Alan Pitt, Children's Hospital, Room 1044, 400 South Kingshighway, St. Louis, MO 63110.

Received for publication 13 January 1992 and in revised form 16 June 1992.

J. Clin. Invest.

(c) The American Society for Clinical Investigation, Inc.

0021-9738/92/11/1978/06 \$2.00

Volume 90, November 1992, 1978-1983 mix with endosomal compartments (4). Because phagosome maturation appears to involve extensive interactions with other intracellular vesicles, we have examined whether specific changes in phagosome protein composition accompany phagosome maturation. Herein we report that the changing protein composition of maturing phagosomes is similar to the changes that occur in endosomes during lysosome biogenesis.

\section{Methods}

Biological materials. J774-E clone, a mannose receptor-positive macrophage cell line, was grown in suspension in minimum essential medium containing Earle's salts and supplemented with $10 \%$ FCS. Before use in an experiment, the cells were pelleted and resuspended in a minimal volume of buffer. Secondary antibodies, Staphylococcus aureus, and purified protein A were radiolabeled with ${ }^{125}$ I using chloramine $T$ (5). Plasma membrane was radioiodinated as previously described (6). Protein concentration was measured according to Bradford using BSA as a standard (7). The following reagents were kindly provided by the indicated persons: mouse monoclonal anti-bovine proton pump antibody (S. Gluck, Washington University, St. Louis, MO); rabbit-anti-mouse $\beta$-glucuronidase (R. Ganshow, Children's Hospital Medical Center, Cincinnati, $\mathrm{OH}$ ); goat anti-human mannose 6-phosphate receptor (W. Sly, St. Louis University, St. Louis, MO); mouse monoclonal (AP.6) anti-bovine alpha-adaptin (F. Brodsky, University of California, San Francisco, San Francisco, CA ). Monoclonal antibody 2.4G2 (rat anti-mouse Fc receptor II) was obtained from American Type Culture Collection, Rockville, MD. Monoclonal antibody 1D4B ( rat anti-mouse LAMP-1 ) was obtained from the Developmental Studies Hybridoma Bank maintained by the Department of Pharmacology and Molecular Sciences, Johns Hopkins University School of Medicine, Baltimore, MD, and the Department of Biology, University of Iowa, Iowa City, IA, under contract NO1-HD-6-2915 from the National Institute of Child Health and Development. Rabbit anti-goat IgG, rabbit anti-rat IgG, rabbit anti-mouse IgG and IgM, and protein $A$ were purchased from Accurate Chemical and Scientific Corp. (Westbury, NY).

Phagocytic probe. Formaldehyde-fixed $S$. aureus (IgGsorb; The Enzyme Center, Boston, MA) was washed with HBSA ${ }^{1}$ (Hanks' balanced salt solution buffered with $10 \mathrm{mM}$ 4-(2-hydroxyethyl)-1-piperazineethanesulfonic acid (Hepes) and $10 \mathrm{mM}$ 2-[2-hydroxy-1,1-bis(hydroxymethyl)ethyl]-aminoethanesulfonic acid pH 7.4 and supplemented with $0.1 \%$ BSA). After incubating $200 \mu \mathrm{l}$ of $S$. aureus (10\% suspension, $\sim 4 \times 10^{7}$ particles $/ \mu \mathrm{l}, 2 \mathrm{mg}$ of $\mathrm{IgG} / \mathrm{ml}$-binding capacity) with $200 \mu \mathrm{g}$ of rabbit anti-mouse IgG polyclonal antibody (IgG fraction; Organon Teknika Corp., Rockville, MD) for $1 \mathrm{~h}$ at $20^{\circ} \mathrm{C}$, the particles were washed three times in HBSA and thereafter incubated with $100 \mu \mathrm{g}$ of mouse IgG (IgG fraction; Sigma Chemical Co., St. Louis, MO) for $1 \mathrm{~h}$ at $20^{\circ} \mathrm{C}$. Coated $S$. aureus was washed three times and resuspended in HBSA.

Phagosome isolation. J774-E clone macrophages $\left(3 \times 10^{8}\right.$ cells $)$ were incubated with antibody-coated $S$. aureus $(100 \mu \mathrm{l})$ for $1 \mathrm{~h}$ at $4^{\circ} \mathrm{C}$. Uptake was initiated by the addition of prewarmed HBSA. After 3 min

1. Abbreviations used in this paper: HBE, Hepes-KOH pH 7.2; HBSA, HBSS buffered with $10 \mathrm{mM}$ 4-(2-hydroxyethyl)-1-piperazineethanesulfonic acid. 
at $37^{\circ} \mathrm{C}$, the incubation was stopped by the addition of $4^{\circ} \mathrm{C}$ HBSA. Cells were subsequently washed three times in HBSA at $4^{\circ} \mathrm{C}$ and then chased by the addition of prewarmed HBSA for $0,4,9$, or $15 \mathrm{~min}$. After cooling with $\mathrm{HBSA}$ at $4^{\circ} \mathrm{C}$, the cells were washed two times in $250 \mathrm{mM}$ sucrose, $0.5 \mathrm{mM}$ EGTA, $20 \mathrm{mM}$ Hepes-KOH pH 7.2 (HBE), resuspended in $\mathrm{HBE}$ to $2 \times 10^{8} \mathrm{cells} / \mathrm{ml}$, and then homogenized with 30 strokes of a ball bearing homogenizer. A protease inhibitor cocktail consisting of $2 \mu \mathrm{g} / \mathrm{ml}$ aprotinin, $1 \mathrm{mM}$ PMSF, $2 \mu \mathrm{g} / \mathrm{ml}$ antipain, 2 $\mu \mathrm{g} / \mathrm{ml}$ leupeptin, $2 \mu \mathrm{g} / \mathrm{ml}$ pepstatin $\mathrm{A}$, and $0.1 \mathrm{mM}$ EDTA was included throughout the phagosome isolation procedure. Homogenates were centrifuged at $400 \mathrm{~g}$ for $3 \mathrm{~min}$ to eliminate nuclei and intact cells. The postnuclear supernatant was next centrifuged at $12,000 \mathrm{~g}$ for 1.5 min at $4^{\circ} \mathrm{C}$. The pellet was resuspended in $\mathrm{HBE}$ and loaded onto a sucrose cushion ( $65 \%$ sucrose, $20 \mathrm{mM}$ Hepes- $\mathrm{KOH}$ pH 7.2, $0.5 \mathrm{mM}$ EGTA) and centrifuged at $150,000 \mathrm{~g}$ for $45 \mathrm{~min}$ at $4^{\circ} \mathrm{C}$. The resulting pellet was used as the phagosome fraction. The phagosome preparation was resuspended in $\mathrm{HBE}$ and stored at $-20^{\circ} \mathrm{C}$ until use. The total protein amount in each phagosome preparation was identical regardless of chase time. The efficiency of the phagosome isolation procedure was estimated by quantitating antibody-coated ${ }^{125} \mathrm{I}-\mathrm{S}$. aureus throughout the isolation procedure ( see Results). Phagosomes isolated for electron microscopic examination were isolated after phagocytosis of prebound antibody-coated $S$. aureus for $15 \mathrm{~min}$ at $37^{\circ} \mathrm{C}$.

Western blotting. Equivalent protein aliquots of each phagosome fraction were solubilized in reducing sample buffer, boiled for $3 \mathrm{~min}$, and separated by reducing SDS-polyacrylamide gel electrophoresis. Proteins were subsequently transferred to $0.22 \mu \mathrm{m}$ nitrocellulose in $20 \%$ methanol, $20 \mathrm{mM}$ Tris pH 9.4, and $100 \mathrm{mM}$ glycine at $50 \mathrm{~V}$ for 5 h. Blots were blocked overnight at $4^{\circ} \mathrm{C}$ in blotto ( $5 \%$ Carnation instant milk, $0.05 \%$ Triton X-100, $50 \mathrm{mM}$ Tris pH 7.2, 0.03\% Antifoam-A). Blots were incubated with primary antibodies in blotto for $1 \mathrm{~h}$ at $20^{\circ} \mathrm{C}$ followed by washing three times in blotto for $20 \mathrm{~min}$. Blots were then incubated with radioiodinated secondary antibody and washed as described above. Blots were exposed to Kodak XAR 5 film at $-80^{\circ} \mathrm{C}$. Developed films were analyzed by densitometry followed by excising and weighing densitometric peaks.

\section{Results}

To quantitate alterations in the protein composition of maturing phagosomes we developed a phagosome isolation procedure which takes advantage of both the large size and heavy density of the phagocytic particle, S. aureus. Biochemical and morphological characterization of isolated phagosomes indicates that the procedure yields very pure preparations of phago- somes with little contamination by membranes of the endosomal/lysosomal pathway. To assay for contamination of nonphagosomal membranes during this procedure, the distributions of both plasma membrane and lysosome markers were assessed. As shown in Table I, ${ }^{125}$ I-labeled plasma membrane was unable to pass through the sucrose cushion. Because many intracellular vesicles (e.g., endosomes, Golgi, and trans-Golgi reticulum) are very similar in density to plasma membrane, this result suggests that most organelles do not pellet through the sucrose cushion. Very little B-hexosaminidase activity (a lysosomal marker enzyme) pelleted when homogenates were prepared from cells which had not internalized antibodycoated $S$. aureus (Table I), indicating that lysosomes do not pass through the sucrose cushion. However, $24 \%$ of the $\beta$-hexosaminidase activity passed through the sucrose cushion when samples were prepared from cells which had internalized antibody-coated $S$. aureus for $15 \mathrm{~min}$ (data not shown). Therefore, $\beta$-hexosaminidase activity appears to pellet through the sucrose cushion only when contained within a phagosome. The efficiency of the phagosome isolation procedure was determined by isolating phagosomes which had internalized prebound, antibody-coated ${ }^{125} \mathrm{I}-S$. aureus for 15 min (see Methods). As shown in Table I, 30\% of antibody-coated ${ }^{125} \mathrm{I}-S$. aureus originally located in the postnuclear supernatant pelleted through the sucrose cushion. In addition, electron microscopic examination of the phagosome preparation demonstrated that it consists almost entirely of phagosomes. Fragments of nuclei were occasionally observed (arrowheads, Fig. $1 \mathrm{~A}$ ). Damage to phagosomes during the isolation procedure is exemplified by the presence of non-membrane-bound $S$. aureus (small arrow, Fig. $1 B$ ) as well as $S$. aureus incompletely surrounded by membrane (large arrow, Fig. $1 B$ ). When postnuclear supernatants from surface radioiodinated cells were mixed with antibody-coated $S$. aureus and centrifuged onto the sucrose cushion, no radioactivity was detected in the final pellet (data not shown). This result strongly suggests that very little nonspecific sticking of nonphagosome membrane to free $S$. aureus occurs. Thus, the membrane partially surrounding the $S$. aureus in Fig. $1 B$ most probably represents disrupted phagosomal membrane. Taken together, these results demonstrate that the phagosome isolation procedure described herein yields phagosomes of high purity.

Table I. Analysis of Distribution of J774 Macrophage Subcellular Fractions during the Phagosome Isolation Protocol

\begin{tabular}{lcccc}
\hline \multicolumn{1}{c}{ Cell fraction } & $\begin{array}{c}\text { 125I-Plasma } \\
\text { membrane } \\
\text { (percentage of total) }\end{array}$ & $\begin{array}{c}\text { B-Hex } \\
\text { activity } \\
\text { (percentage of total) }\end{array}$ & $\begin{array}{c}\text { 125I-S. aureus } \\
\text { (percentage of total) }\end{array}$ & $\begin{array}{c}\text { Protein } \\
\text { (percentage of total) }\end{array}$ \\
\hline Postnuclear supernatant & 100 & 100 & 100 & 100 \\
$12,000 \mathrm{~g}$ phagosome pellet & 50 & 38 & 91 & 54 \\
$65 \%$ sucrose pellet & 0.51 & 0.14 & 30 & 4 \\
\hline
\end{tabular}

The isolation of phagosomes initially involved homogenizing cells followed by low speed centrifugation of homogenate to remove unbroken cells and nuclei thereby yielding a postnuclear supernatant. Postnuclear supernatants were subsequently centrifuged at $12,000 \mathrm{~g}$ for $1.5 \mathrm{~min}$. to purify phagosomes partially. Lastly, the membrane pellet (containing most of the phagocytic particles) was resuspended, loaded onto a $65 \%$ sucrose cushion, and centrifuged $150,000 \mathrm{~g}$ for $45 \mathrm{~min}$. The resulting pellet was used as the phagosome fraction. The distributions of plasma membrane and lysosomes at three stages of this protocol (the stages are identified in the left column) were determined by performing the above isolation protocol on a population of cells that did not phagocytose $S$. aureus. Fractions were then assayed for both the distribution of radioiodinated plasma membrane and $\beta$-hexosaminidase activity (lysosome marker). The yield of phagosomes at these three steps of the protocol was determined by assaying for the presence of the phagosome marker, ${ }^{125} \mathrm{I}-S$. aureus, in subcellular fractions of another population of $\mathrm{J} 774$ macrophages that had internalized prebound antibody-coated ${ }^{125} \mathrm{I}-S$. aureus for $15 \mathrm{~min}$ at $37^{\circ} \mathrm{C}$. 

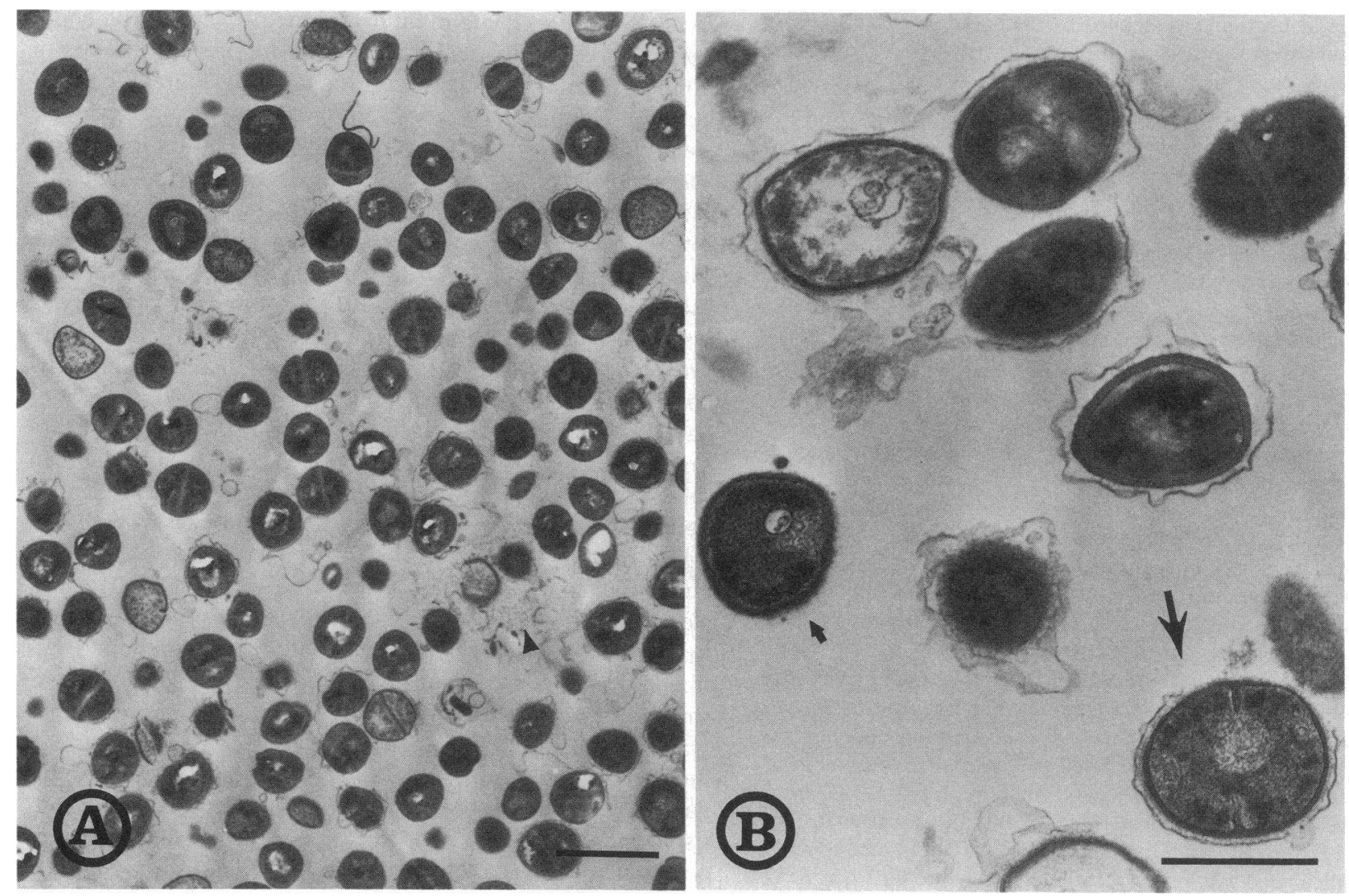

Figure 1. Electron micrographs of a phagosome preparation obtained as described in Methods. Arrowhead in $A$ depicts fragments of nuclei. Small arrow in $B$ identifies $S$. aureus not surrounded by membrane. Large arrow in $B$ identifies $S$. aureus partially surrounded by membrane. Bar in $A=1 \mu \mathrm{m} ;$ bar in $B=0.5 \mu \mathrm{m}$.

Previous studies in our laboratory showed that within 10 min of phagocytosis, both endosomes and lysosomes fuse to phagosomes (2). In addition, extensive recycling of phagosomal contents occurs and hydrolytic activity increases within this time period (4). The functional and morphological changes occurring in the maturing phagosome suggest that differences in the phagosome's proteins composition also arise during this time period. Thus, to analyze the effect of increasing times of phagocytosis on phagosomal protein composition, phagosomes were isolated after 3-18 min of phagocytosis and subjected to both SDS-PAGE and Western blot analysis. J774E clone mouse macrophages internalized $S$. aureus for $3 \mathrm{~min}$ at $37^{\circ} \mathrm{C}$ after which the cells were washed and reincubated at $37^{\circ} \mathrm{C}$ for $0,4,9$, or $15 \mathrm{~min}$. Phagosomes isolated from these cells were subjected to one-dimensional SDS-PAGE followed by silver staining. As shown in Fig. 2, despite different times of phagocytosis, the phagosomal protein compositions are largely identical. Western blot analysis of the isolated phagosomes, however, reveals relative increases and decreases in antigen signal intensities (Fig. 3). Antigens whose signals decrease with increasing chase time are alpha-adaptin, the mannose receptor, and the FcII receptor. Alpha-adaptin and mannose receptor signal intensity falls most dramatically while the FcII receptor signal falls slightly. Antigens whose signals increase with increasing chase time are the $31-\mathrm{kD}$ subunit of the proton pump, cathepsin D, $\beta$-glucuronidase, LAMP-1, and the cation-dependent mannose 6-phosphate receptor. Thus, while results from SDS-PAGE analysis reveal few differences in the total protein composition among phagosomes of different maturity, Western blot analyses reveals that phagosomes undergo substantial changes in their content of specific proteins.

\section{Discussion}

Professional phagocytic cells internalize large extracellular particles into intracellular vacuoles termed phagosomes. In macrophages, a newly formed phagosome functionally transforms into a degradative compartment termed a phagolysosome (1,

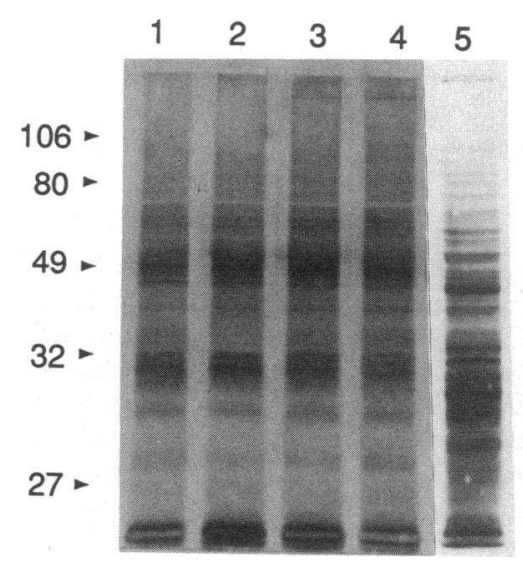

Figure 2. SDS-PAGE and silver stain of phagosome preparations. Phagosome preparations $(3 \mu \mathrm{g})$, were isolated after $3 \mathrm{~min}$ internalization and 0 (lane 1), 4 (lane 2), 9 (lane 3 ), or 15 (lane 4) min of chase. The total membrane fraction obtained by high speed centrifugation of a postnuclear supernatant is separated in lane 5 . Molecular weight markers in kilodaltons are given on left of lanes. 

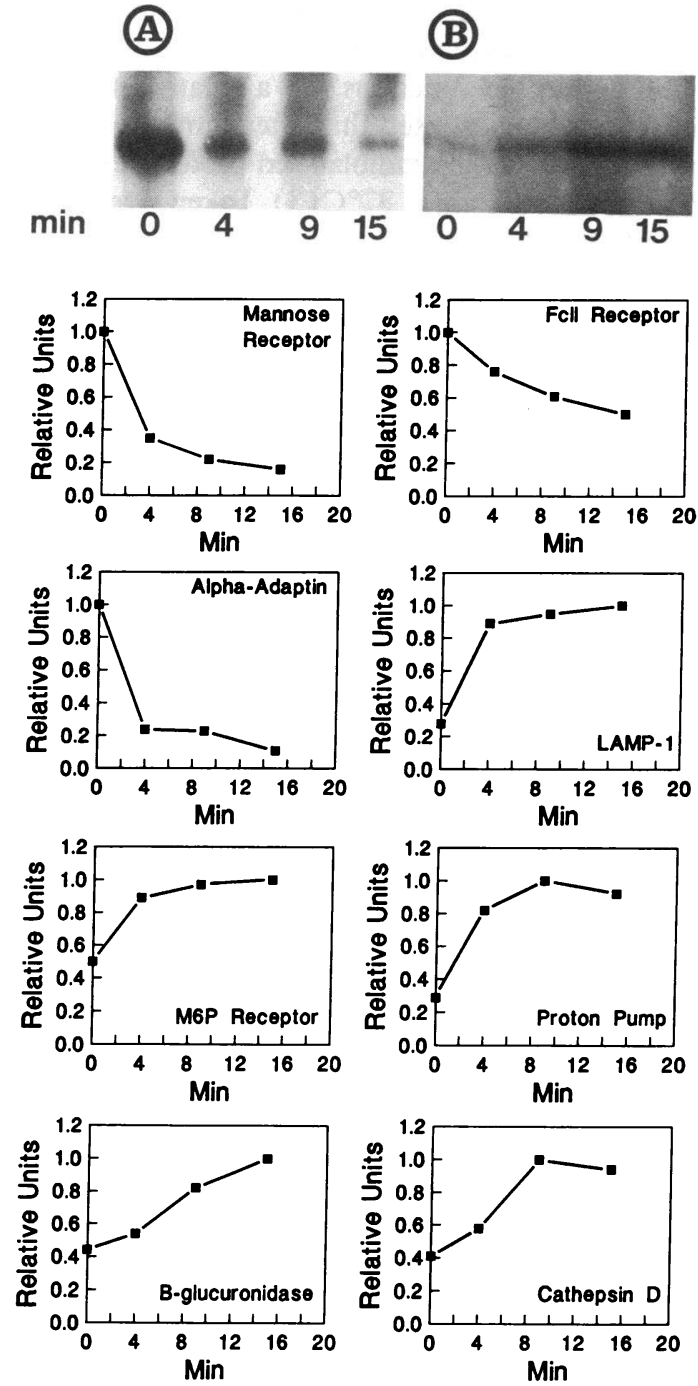

Figure 3. Western blot analyses of phagosome preparations. Phagosomes were isolated after three minutes of internalization at $37^{\circ} \mathrm{C}$ followed by $0,4,9$, or $15 \mathrm{~min}$ of chase at $37^{\circ} \mathrm{C}$. Equal amounts of phagosome proteins were separated by SDS-PAGE and transferred to nitrocellulose. Following blocking of nitrocellulose in blotto, primary antibodies and radioiodinated secondary reagents were separately incubated with the blots. Autoradiographs shown are from western blot analysis of alpha-adaptin $(A)$ and cathepsin $\mathrm{D}(B)$. From left to right, lanes represent chase times of $0,4,9$, and $15 \mathrm{~min}$. $(C)$ Quantitation of Western blots of phagosome preparations. Autoradiographs of blots were quantified by cutting out and weighing densitometric peaks. Values are normalized by setting the largest value in each experiment to 1.0 .

4, 8-10). Recent biochemical and morphological studies revealed that the transformation process includes an initial period of extensive phagosome-endosome fusion followed by extensive phagosome-lysosome fusion (2). These results suggest that phagosomes initially acquire endosome functions, such as protein recycling, and then, following lysosome-phagosome fusion, acquire the degradative functions of lysosomes. Consistent with this model for phagolysosome biogenesis are demonstrations that newly formed phagosomes, like early endosomes, recycle phagocytosed material to the cell surface $(3,4)$. If pha- gosome and endosome fusion is continuous as well as extensive, one would predict that compositional changes occurring in maturing phagosomes parallel compositional changes observed in maturing endosomes. Thus, to investigate the effects of phagosome maturation on phagosome protein composition, isolated phagosomes of different maturity were isolated and examined by SDS-PAGE and western blot analysis. The results indicate that numerous phagosomal proteins can increase or decrease in abundance during phagosome maturation. Furthermore, the phagosome compositional changes parallel protein compositional changes known to occur in maturing endosomes.

With increasing times of phagocytosis, we observed a decrease in phagosomal FcII receptor, mannose receptor, and alpha-adaptin. Mellman and colleagues previously demonstrated that while aggregated IgG targets cell surface FcII receptor to lysosomes, endocytosis of monomeric IgG results in rapid recycling of the receptor through endosomes $(11,12)$. Although the phagocytic particles in the present study initially contained aggregated IgG, we observed a moderate decrease in FcII receptor in our Western blots ( $50 \%$ at $15 \mathrm{~min}$ ), suggesting that some FcII receptor recycling occurred. However, we previously demonstrated that upon phagocytosis in our experimental system, a fraction of the antibody coating the phagocytic particle is proteolytically separated from the particle (4). Thus, monomeric antibody generated within the phagosome may subsequently signal phagosomal FcII receptor to recycle, and thus explain the observed FcII receptor loss.

The mannose receptor mediates endocytosis of mannosylated proteins (13). It constitutively recycles from endosomes to the plasma membrane at a rate of $\sim 7 \mathrm{~min} /$ cycle. Although phagocytosis in the experiments reported herein was Fc receptor mediated, the mannose receptor also entered phagosomes. As seen in Fig. 3, phagosomal mannose receptor decreased $65 \%$ during the first $4 \mathrm{~min}$ of chase. This rate of decrease approximates the rate at which the mannose receptor recycles from endosomes. A plausible mechanism responsible for mannose receptor loss is a protein recycling mechanism similar to that employed by the endocytic pathway.

Adaptins are a family of peripheral membrane proteins that serve to link clathrin lattices to specialized receptors of plasma and trans-Golgi reticulum membranes $(14,15)$. Alpha-adaptin specifically associates with plasma membrane clathrin coats and appears to dissociate after removal of the clathrin coat (16). Earlier studies from our laboratory and others demonstrated that forming phagosomes contain clathrin lattices on their surface but that they are quickly lost upon completion of particle engulfment $(4,17)$. Thus, the very rapid decrease $\left(t_{1 / 2}\right.$ $=2 \mathrm{~min}$ ) in phagosomal alpha-adaptin seen in Fig. 3 is consistent with earlier studies on phagosome-associated clathrin lattices.

While protein recycling from the phagosome may account for the observed losses in antibody recognition of the mannose receptor, the FcII receptor, and alpha-adaptin, proteolytic degradation of the antigens may also occur. However, for several reasons, we believe it is unlikely that these antigens are being degraded during the course of the experiment. First, no degradation products were observed on any of the Western blots. Second, alpha-adaptin is a peripheral membrane protein and thus should not be affected by the introduction of proteases into the maturing phagosome. Third, the mannose and FcII 
receptors normally are recycling receptors that continually cycle through protease containing (endosomal/lysosomal) compartments yet are not significantly degraded. Thus, $18 \mathrm{~min}$ of internalization is unlikely to account for the substantial losses observed in Figure 3.

Western blot analysis also demonstrated the accumulation of several proteins in phagosomes. The $31-\mathrm{kD}$ subunit of the vacuolar proton pump increased 2-3-fold during the initial 4 min of chase (Fig. 3 ). The increase in the proton pump signal as phagosomes mature is consistent with previous reports on the increase in acidity from endosomes to lysosomes (18). The acid proteases, cathepsin $D$ and $\beta$-glucuronidase, increased approximately 2-3-fold during the $15 \mathrm{~min}$ of chase (Fig. 3 ). The difference in the rate of increase of the proteases compared to that of the proton pump is consistent with the finding of McNeil et al. who showed that phagosome acidification precedes the onset of proteolysis (19).

The cation-dependent mannose- 6 phosphate receptor and LAMP-1 displayed similar rates of increase during phagolysosome formation. LAMP-1 is a heavily glycosylated membrane protein of unknown function located primarily in lysosomes and endosomes (20). Its presence in phagosomes is relatively low after $3 \mathrm{~min}$ of internalization but quickly increases to near maximal levels by $7 \mathrm{~min}$. This distribution is similar to the findings of August et al. who showed that LAMP-1 increases in abundance from endosomes to lysosomes (21). The cation-dependent mannose- 6 phosphate receptor also shows a marked increase between 3 and 7 min of phagocytosis. Von Figura and colleagues localized the majority of this receptor predominantly to vesicles surrounding the trans-Golgi reticulum as well as late endosomes (22). Possibly, efficient receptor recycling from late endosomes results in its absence from lysosomes (23). Because we did not observe a decrease in cation-dependent mannose- 6 phosphate receptor receptor after its initial rise, our results suggest that either phagosomes cannot efficiently recycle this receptor or that phagosomes do not fully mature into phagolysosomes within the $18 \mathrm{~min}$ of phagocytosis observed herein.

Phagocytic particle opsonization may influence phagosome protein compositional changes. Joiner et al. recently reported that neutrophil phagocytosis of particles opsonized with C3 fragments leads to decreased specific granule-phagosome fusion compared to particles opsonized with antibody (24). As a consequence, phagosomes containing antibody-coated particles may contain more specific granule components than phagosomes containing $\mathrm{C} 3 \mathrm{~b}$-coated particles. The extent of azurophilic granule-phagosome fusion was the same with both opsons. Also, microscopic and biochemical examination of vacuoles in Fc receptor-transfected fibroblasts reveals great differences depending on whether cells phagocytose uncoated or antibody-coated Toxoplasma gondii (25). While antibodycoated particles enter degradative compartments surrounded by protein-rich membrane, uncoated Toxoplasma gondii enter compartments that are both bounded by protein-poor membrane and contain less hydrolytic activity. Active participation of Toxoplasma gondii is thought to contribute to this phenomena. Thus, changes in the phagosome protein composition, assayed as described in this report, may differ when examined together with different phagocytic particles.

Our results from SDS-PAGE analysis of isolated phagosomes indicate that the phagosome protein composition re- mains relatively constant during phagosome maturation, suggesting that only a minority of phagosomal proteins are responsible for phagosome-specific functions. In a related study, Muller and colleagues demonstrated that after intraphagosomal radioiodination, most of the radiolabeled proteins exited the phagosome within $15-30 \mathrm{~min}$ at $37^{\circ} \mathrm{C}(3)$. Taken together, our results suggest that the majority of vesicles that fuse to maturing phagosomes are similar in protein composition to the recipient phagosomes. As a result, the vesicle-phagosome fusions associated with phagosome maturation do not greatly change the phagosome protein composition. Our results are consistent with those of Enrich et al. who, using density gradient centrifugation, observed that the protein compositions of hepatocyte early and late endosomes are very similar (26). To the contrary, Schmid et al., reported that Chinese hamster ovary early and late endosomes isolated by free flow electrophoresis display different protein compositions (27). These contrasting results possibly reflect differences in the vesicle isolation protocols used by ourselves and others.

In conclusion, the data presented in this report demonstrate that the phagosome protein composition changes during its transformation into a phagolysosome. Furthermore, the observed compositional changes and the rates of these changes are largely consistent with a maturational model for phagolysosome formation whereby early phagosomes interact extensively with endosomes and lysosomes, thereby acquiring their characteristic proteins, membrane constituents, and physiological functions.

\section{Acknowledgments}

A. L. Schwartz is supported by National Institutes of Health grant GM38284; P. D. Stahl is supported by National Institutes of Health grants GM42259, AI20015, and DK40535. L. S. Mayorga is supported by a Rockefeller Foundation Biotechnology Career Fellowship.

\section{References}

1. Silverstein, S. C., S. Greenberg, F. Di Virgilio, and T. H. Steinberg. 1989. Phagocytosis. In Fundamental Immunology. W. E. Paul, editor. Raven Press, Ltd., New York. 703-719.

2. Mayorga, L. M., F. Bertini, and P. D. Stahl. 1991. Fusion of newly formed phagosomes with endosomes in intact cells and in a cell-free system. J. Biol. Chem. 266:6511-6517.

3. Muller, W. A., R. M. Steinman, and Z. A. Cohn. 1980. The membrane proteins of the vacuolar system II. Bidirectional flow between secondary lysosomes and plasma membrane. J. Cell Biol. 86:304-314.

4.Pitt, A., L. S. Mayorga, A. L. Schwartz, and P. D. Stahl. 1991. Recycling of phagosomal components to an endosomal compartment. J. Biol. Chem. 267:126-132.

5. Hunter, W. M., and F. C. Greenwood. 1962. Preparation of iodine-131 labelled human growth hormone of high specific activity. Nature (Lond.). 194:495-498.

6. Hubbard, A. L., and Z. A. Cohn. 1975. Externally disposed plasma membrane proteins I. Enzymatic iodination of mouse L cells. J. Cell Biol. 64:438-460.

7. Bradford, M. M. 1976. A rapid and sensitive method for the quantitation of microgram quantities of protein by the principle of protein-dye binding. Anal. Biochem. 72:248-254.

8. Muller, W. A., R. M. Steinman, and Z. A. Cohn. 1980. The membrane proteins of the vacuolar system I. Analysis by a novel method of intralysosomal iodination. J. Cell Biol. 86:292-303.

9. Hubbard, A. L., and Z. A. Cohn. 1975. Externally disposed plasma membrane proteins II. Metabolic fate of iodinated polypeptides of mouse $\mathrm{L}$ cells. $J$. Cell Biol. 64:461-479.

10. Muller, A. W., R. M. Steinman, and Z. A. Cohn. 1983. Membrane proteins of the vacuolar system. III. Further studies on the composition and recycling of endocytic vacuole membrane in cultured macrophages. J. Cell Biol. 96:29-36.

11. Mellman, I., H. Plutner, R. M. Steinman, J. C. Unkeless, and Z. A. Cohn. 1983. Internalization and degradation of macrophage Fc receptors during receptor-mediated phagocytosis. J. Cell Biol. 96:887-895. 
12. Mellman, I., H. Plutner, and P. Ukkonen. 1984. Internalization and rapid recycling of macrophage $\mathrm{Fc}$ receptors tagged with monvalent antireceptor antibody: possible role of a prelysosomal compartment. J. Cell Biol. 98:1163-1169.

13. Stahl, P. D., P. H. Schlesinger, E. Sigardson, J. S. Rodman, and Y. C. Lee. 1980. Receptor-mediated pinocytosis of mannose glycoconjugates by macrophages: characterization and evidence for receptor recycling. Cell. 19:207-215.

14. Brodsky, F. M. 1988. Living with clathrin: its role in intracellular membrane traffic. Science (Wash. DC). 242:1396-1402.

15. Pearse, B. M. F., and M. S. Robinson. 1990. Clathrin, adaptors, and sorting. Annu. Rev. Cell Biol. 6:151-171.

16. Guagliardi, L. E., B. Koppelman, J. S. Blum, M. S. Marks, P. Cresswell, and F. M. Brodsky. 1990. Co-localization of molecules involved in antigen processing and presentation in an early endocytic compartment. Nature (Lond.). 343:133-139.

17. Aggeler, J., and Z. Werb. 1982. Initial events during phagocytosis by macrophages viewed from outside and inside the cell: membrane-particle interactions and clathrin. J. Cell Biol. 94:613-623.

18. Mellman, I., R. Fuchs, and A. Helenius. 1986. Acidification of the endocytic and exocytic pathways. Annu. Rev. Biochem. 55:663-700.

19. McNeil, P. L., L. Tanasugarn, J. B. Meigs, and D. L. Taylor. 1983. Acidifcation of phagosomes is initiated before lysosomal enzyme activity is detected. $J$. Cell Biol. 97:692-702.
20. Hughes, E. N., and J. T. August. 1981. Characterization of plasma membrane proteins identified by monoclonal antibodies. J. Biol. Chem. 256:664-671.

21. D'souza, M. P., and J. T. August. 1986. A kinetic analysis of biosynthesis and localization of a lysosome-associated membrane glycoprotein. Arch. Biochem. Biophys. 249:522-532.

22. Bleekemolen, J. E., M. Stein, K. von Figura, J. W. Slot, and H. J. Geuze. 1988. The two mannose 6-phosphate receptors have almost identical subcellula distributions in U937 monocytes. Eur. J. Cell Biol. 47:366-372.

23. Kornfeld, S., and I. Mellman. 1989. The biogenesis of lysosomes. Annu. Rev. Cell Biol. 5:483-525.

24. Joiner, K. A., T. Ganz, J. Albert, and D. Rotrosen. 1989. The opsonizing ligand on Salmonella typhimurium influences incorporation of specific, but not azurophil, granule constituents into neutrophil phagosomes. J. Cell Biol. 109:2771-2782.

25. Joiner, K. A., S. A. Fuhrman, H. M. Miettinen, I. Kasper, and I. Mellman. 1990. Toxoplasma gondii: fusion competance of parisitophorous vacuoles in $\mathrm{Fc}$ receptor-transfected fibroblasts. Science (Wash. DC). 249:641-649.

26. Enrich, C., P. Tabona, and W. H. Evans. 1990. A two-dimensional electrophoretic analysis of the proteins and glycoproteins of liver plasma membrane domains and endosomes. Biochem. J. 271:171-178.

27. Schmid, S. L., R. Fuchs, P. Male, and I. Mellman. 1988. Two distinct subpopulations of endosomes involved in membrane recycling and transport to lysosomes. Cell. 52:73-83. 